\title{
Probe development of CMUT and PZT row-column-addressed 2-D arrays
}

Engholm, Mathias; Bouzari, Hamed; Christiansen, Thomas Lehrmann; Beers, Christopher; Bagge, Jan Peter; Moesner, Lars Nordahl; Diederichsen, Søren Elmin; Stuart, Matthias Bo; Jensen, Jørgen Arendt; Thomsen, Erik Vilain

Published in:

Sensors and Actuators A: Physical

Link to article, DOI:

10.1016/j.sna.2018.02.031

Publication date:

2018

Document Version

Peer reviewed version

Link back to DTU Orbit

Citation (APA):

Engholm, M., Bouzari, H., Christiansen, T. L., Beers, C., Bagge, J. P., Moesner, L. N., Diederichsen, S. E., Stuart, M. B., Jensen, J. A., \& Thomsen, E. V. (2018). Probe development of CMUT and PZT row-columnaddressed 2-D arrays. Sensors and Actuators A: Physical, 273, 121-133.

https://doi.org/10.1016/j.sna.2018.02.031

\section{General rights}

Copyright and moral rights for the publications made accessible in the public portal are retained by the authors and/or other copyright owners and it is a condition of accessing publications that users recognise and abide by the legal requirements associated with these rights.

- Users may download and print one copy of any publication from the public portal for the purpose of private study or research.

- You may not further distribute the material or use it for any profit-making activity or commercial gain

- You may freely distribute the URL identifying the publication in the public portal 


\title{
Probe development of CMUT and PZT Row-Column-Addressed 2-D Arrays
}

\author{
Mathias Engholm $^{\mathrm{a}}$, Hamed Bouzari ${ }^{\mathrm{b}}$, Thomas Lehrmann Christiansen ${ }^{\mathrm{a}}$, Christopher Beers ${ }^{\mathrm{c}}$, Jan Peter Bagge ${ }^{\mathrm{d}}$, \\ Lars Nordahl Moesner ${ }^{\mathrm{d}}$, Søren Elmin Diederichsen ${ }^{\mathrm{a}}$, Matthias Bo Stuart ${ }^{\mathrm{b}}$, Jørgen Arendt Jensen ${ }^{\mathrm{c}}$, Erik Vilain Thomsen ${ }^{\mathrm{a}}$ \\ ${ }^{a}$ Department of Micro- and Nanotechnology, DTU Nanotech, Technical University of Denmark, Building 345C, DK-2800 Kgs. Lyngby, Denmark \\ ${ }^{b}$ Center for Fast Ultrasound Imaging, Department of Electrical Engineering, Technical University of Denmark, Building 349, DK-2800 Kgs. Lyngby, Denmark \\ ${ }^{c}$ Sound Technology Inc., Analogic Ultrasound Group, PA-16803, USA \\ ${ }^{d}$ BK Ultrasound ApS, Analogic Ultrasound Group, Herlev, Denmark
}

\begin{abstract}
This paper presents the characterization of two prototyped fully integrated $62+62$ row-column-addressed (RCA) 2-D transducer array probes, which are based on capacitive micromachined ultrasonic transducer (CMUT) and on piezoelectric transducer (PZT) technology, respectively. Both transducers have integrated apodization to reduce ghost echoes and were designed with similar acoustical features i.e. $3 \mathrm{MHz}$ center frequency, $\lambda / 2$-pitch and $24.8 \times 24.8 \mathrm{~mm}^{2}$ active footprint. The transducer arrays were assembled in a 3-D printed probe handle with electromagnetic shield and integrated electronics for driving the 128-channel coaxial cable to the scanner. The electronics were designed to allow all elements, both rows and columns, to be used interchangeably as either transmitters or receivers. The transducer characterization i.e. bandwidth, phase delay, surface pressure, sensitivity, insertion loss, and acoustical crosstalk, were based on several single element measurements, including pressure and pulse-echo, and were evaluated quantitatively and comparatively. The weighted center frequency was $3.0 \mathrm{MHz}$ for both probes and the measured $-6 \mathrm{~dB}$ fractional bandwidth was $109 \pm 4 \%$ and $80 \pm 3 \%$ for the CMUT and the PZT probe, respectively. The surface pressures of the CMUT and PZT were $0.55 \pm 0.06 \mathrm{MPa}$ and $1.68 \pm 0.09 \mathrm{MPa}$, respectively, and the receive sensitivities of the rows (receiving elements) were $12.9 \pm 0.7 \mu \mathrm{V} / \mathrm{Pa}$ and $13.7 \pm 2.1 \mu \mathrm{V} / \mathrm{Pa}$.
\end{abstract}

Keywords: CMUT, PZT, Row-column-addressing, Ultrasound, Volumetric Imaging

\section{Introduction}

For the last 30 years, time resolved 3-D (4-D) imaging has received considerable interest, since it offers several advantages over conventional 2-D imaging. Images acquired using a traditional 2-D probe are dependent on position and scan angle. This makes some imaging planes inaccessible due to the anatomy of the human body. Volumetric imaging does not have the same drawback, since any view angle is possible from the volume data. It also offers more accurate estimation of the size of organs, cysts, and tumors without relying on the assumptions and the operator skills needed when using 2-D imaging estimations.

To obtain real time-resolved volumetric imaging with frame rates higher than $20 \mathrm{~Hz}, 2-\mathrm{D}$ transducer arrays are necessary $[1,2]$. Such transducers were first seen in the early $1990 \mathrm{~s}$ [3]. By placing the elements in a rectangular grid, the beam can be steered electronically in two perpendicular directions (azimuth and elevation) and hereby acquire data from a volume. To obtain an image quality similar to that of a 1-D transducer, the same number of elements in both lateral dimensions is needed. A 1-D array of 128 elements would translate into $128 \times 128=16,384$ elements in a $2-\mathrm{D}$ matrix array. From a transducer fabrication perspective, this poses a great challenge for providing electrical connections to all the elements while maintaining a high element yield. The interconnecting wires between the 16,384 elements and the ultrasonic system result in a large, heavy cable, which excludes it from any practical use.

The issue of reducing channel counts, whilst maintaining the size of the array aperture, was addressed in the earlier versions of 2-D matrix arrays by introducing sparse arrays. Here only a subset of elements is active at the same time. Amongst these are Mills cross arrays, random arrays, and Vernier arrays, each presenting their benefits and drawbacks [4-8]. However, all of them suffer from reduced signal-to-noise ratio (SNR), due to the reduced active area, and they introduce higher sidelobes and/or grating lobes. Recently, fully populated arrays with reduced channel count have become available by integrating electronic pre-beamformers inside the transducer probe [9-11]. Approaches to include the integrated circuit (IC) directly on a capacitive micromachined ultrasonic transducer (CMUT) has also been investigated, both by flip-chip bonding the CMUT to the IC [12-14] and by monolithically integrating the CMUT on the CMOS $[15,16]$. Integrating the electronics in the handle can result in much fewer signals to be funneled out to the ultrasound scanner. An example of such a state-of-the-art fully populated matrix transducer, is the X6-1 PureWave xMATRIX Array from Phillips (Eindhoven, Netherlands), with 9,212 elements. Despite the recent advances in real-time 3-D ultrasound imaging, the ultrasound systems supporting such imaging modalities are highly advanced and rely on cutting edge software, hardware, and manufacturing technology. This results in expensive equipment that impairs the low-cost advantage of ultrasound, and 
thus limits its more widespread use. Moreover, the thermal budget starts to become a consideration for modern probes with integrated electronics, due to the constraints on transducer probe heating that are dictated by the standards for medical equipment $[17,18]$.

Recently, an alternative to fully addressed matrix arrays has been suggested: the row-column-addressed (RCA) 2-D arrays. These were first proposed in 2003 by Morton and Lockwood [19]. Row-column-addressing of 2-D arrays is a scheme to reduce the number of active channels needed for contacting the elements in the array. The idea is to contact the elements in the 2-D array either by their row or column indices. Each row or column thereby acts as one large element. This effectively turns the array into two orthogonal 1-D arrays. The imaging principle relies on using one of the 1-D arrays as the transmit array, creating a line focus of the transmit pulse. The perpendicular 1-D array is used to receive, and enable receive focus in the orthogonal dimension. The combination of transmit and receive focus provides focusing on a point in the volume; hence a volumetric image can be created. While a $N \times N$ fully addressed array needs $N^{2}$ connections, a RCA array only needs $2 N$ connections. The RCA array can therefore have a larger aperture compared to the fully addressed array, with the same number of connections. The simulation study [20] and the measurements study [21], both by Rasmussen and Jensen, compared the two different addressing schemes. With the same number of connections, a superior image quality is obtained using the RCA array.

An inherent drawback of the row-column-addressing, is that the long elements produce considerable edge effects, leading to ghost echoes in the beamformed image. Since the elements do not allow electronic control along their length, the ghost echoes cannot be removed with conventional electronic apodization. This issue was first addressed by Démoré et al. [22] and later studied in detail by Rasmussen and Jensen [20]. Both studies concluded that integrating the apodization in the transducer itself was an effective way of solving the issue. Several ways of realizing the integrated apodization have been suggested, including a variable polarization of the piezo ceramic material [23] and varying the density of CMUT cells [24].

Several groups have previously presented realizations of RCA arrays. The first experimental demonstration of RCA arrays was presented in 2006 by Seo and Yen [25]. The array was a piezoelectric transducer (PZT) in a 64+64 layout, fabricated using a 1-3 ceramic with the row and column electrodes defined on separate sides of the ceramic. The same authors later surpassed this array with a $256+256$ array using the same fabrication technique [26-28]. In 2009, Yen et al. introduced a simplified process for fabrication of RCA PZT arrays using a dual layer structure [29]. The dual layer structure was composed of a piezoelectric 2-2 composite for the transmit array, and a single sheet of undiced copolymer for the receive array. In 2009, the first RCA arrays based on CMUT technology were presented by Logan et al. [30]. They showed a 32+32 array fabricated using the wafer bonding process with a silicon nitride plate, and later they presented characterization of a similar array [31]. Zemp et al. [32] and Sampaleanu et al. [33] presented RCA arrays fabri- cated using the sacrificial release process and performed feasibility studies. More recently they have presented photoacoustic imaging using RCA CMUT arrays [34]. In 2015 Rasmussen et al. [35] and Christiansen et al. [36] presented a two-part paper presenting a RCA array with integrated apodization. In part I, the apodization was added as a static roll-off apodization region located at the ends of the line elements. They showed that the main lobe was unaffected by integrating this type of apodization. Part II showed experimental results of a CMUT RCA 2-D array with this roll-off apodization. The CMUT array had a $62+62$ layout with four apodization regions fabricated using the wafer bonding technique, two SOI wafers and a plate of highly doped silicon. In 2016 Zeshan et al. [37] presented a 32+32 RCA CMUT array fabricated using an anoding bonding process. It was designed to provide a solution for micro-particle trapping and handling.

This paper describes the experimental results of two RCA 2-D array probes, one based on CMUT technology and another based on PZT technology. The probes are fully integrated RCA 2-D arrays equipped with integrated hardware apodization. Both of the transducers are designed with similar acoustical features, i.e. dimensions, center frequency, and packaging, and both plugged into the research ultrasound scanner, SARUS [38]. This gives the unique possibility of comparing the two probes and evaluating the row-column addressing scheme based on two different technologies. The scope of this paper is therefore to display the capabilities of RCA transducers, when integrated into probe handles, and to evaluate their performance. The design and fabrication are described, and the characterization of the two probes is based on acoustical measurements. Based on these measurements the center frequency, bandwidth, phase delay, surface pressure, sensitivity, insertion loss, and acoustical crosstalks are evaluated and discussed.

Initial results of this study have been published in a conference paper [39] describing the development of the CMUT RCA probe. The description of array design, fabrication, electronics and probe assembly are partially included in this paper and extended as another probe was developed based on PZT technology and using the same hardware architecture as the CMUT probe. This study extends the characterization of the CMUT probe by also reporting the bandwidth, phase delay, surface pressure, sensitivity, insertion loss, and acoustical crosstalks across the array, thereby presenting a full characterization of both probes.

This paper is organized as follows: Section 2 describes the general design of the RCA transducer followed by the fabrication of both the CMUT and the PZT array. Section 3 describes the assembly of the probe and the integrated electronics. Section 4 introduces the five different measurement set-ups and Section 5 contains the results from the characterization of the arrays. Section 6 features a discussion of the results and comparison of the two technologies. Finally, a conclusion is presented in Section 7. 


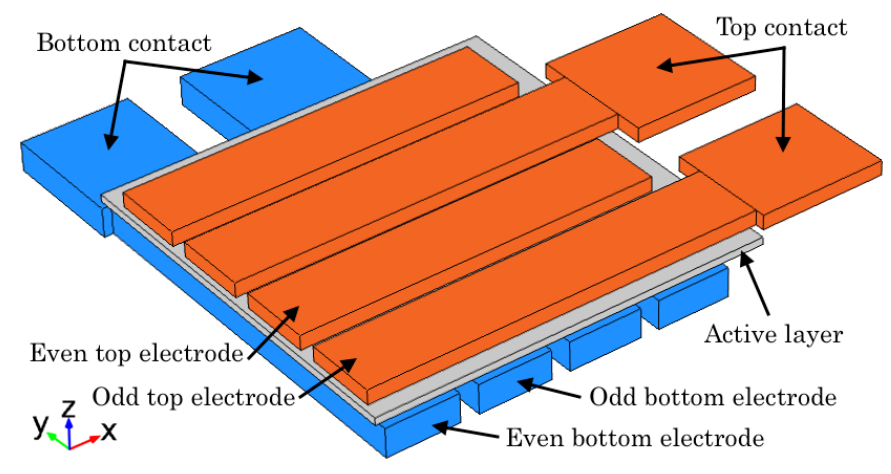

Figure 1: 3-D illustration of a RCA transducer array showing a corner with four top and four bottom electrodes. The top electrode is colored orange and the bottom electrode blue. The gray part between the electrodes is the active part, either PZT or CMUT.

\section{Array design and fabrication}

The general design of the RCA arrays is based on the findings by Rasmussen et al. [35] and Christiansen et al. [36]. The arrays consist of 62 row elements and 62 column elements, and four apodization regions. Only the $62+62$ elements are connected to beamformer channels. The design of the RCA array can therefore be divided into two parts: The central region and the apodization region.

The central part of the array may be considered as a conventional RCA array. A 3-D diagram of a corner of such an array is shown in Fig. 1. The diagram includes four top and four bottom electrodes placed orthogonal to each other, here colored orange and blue, respectively. Between the top and bottom electrodes is the "active" material, which either is the CMUTs or the piezoelectric material. The element contacts are placed alternately on each side of the array as showed in the figure. The top elements can be used as a 1-D array by grounding all of the bottom elements, and the bottom elements can be used as an orthogonal 1-D array by grounding all of the top elements.

The four apodization regions are located outside the central part of the array and are added to avoid abrupt truncation of the elements, which gives rise to ghost echoes [35]. The array layout including the apodization is shown in Fig. 2. The central part is showed within the dashed lines and has an apodization value of 1 . The apodization regions are placed on each side of the central region, and the apodization value follows a Hann function from the edge of the central part to the edge of the array, where the apodization is 0 . The apodization was originally developed for the CMUT array [36], but for the PZT array it has been fabricated to have the same dimension and roll-off characteristic.

Two arrays are fabricated using the design introduced above, one based on CMUT technology and another based on PZT technology. The pitch, number of elements, active footprint, center frequency, and excitation voltage are identical for the two arrays. This makes it possible to evaluate and compare the row-column-addressing scheme based on these two different technologies. A center frequency of $3 \mathrm{MHz}$ was chosen with half wavelength pitch and an excitation voltage of $\pm 75 \mathrm{Vac}$. The

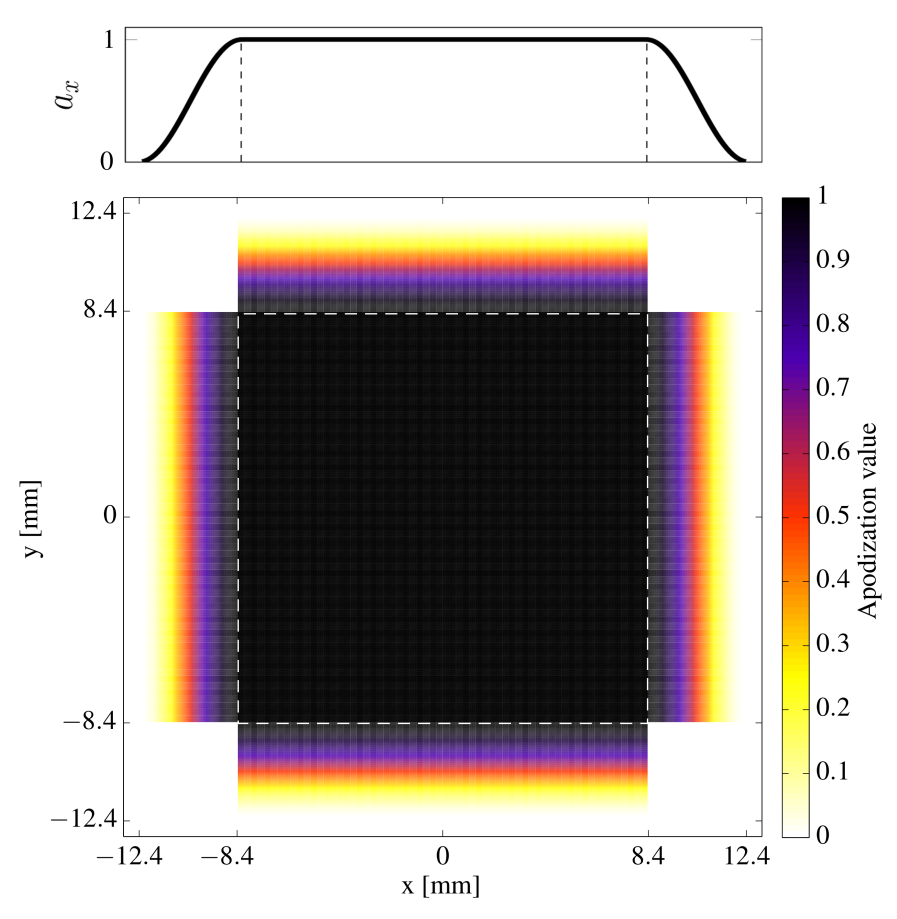

Figure 2: A sketch of the device layout, including apodization roll-off region. Colors represent the apodization value. $a_{x}$ represents the lateral profile of the apodization.

dimensional parameters of both arrays are given in Table 1.

\section{1. $C M U T$}

The CMUT array layout was identical to the design introduced by Christiansen et al. [36]. This design employed 16 square cells in each sub element (crossing of a row and a column element) and the apodization regions were implemented by decreasing the number of cells. Apodization value one corresponded to 16 cells in a sub-element, and apodization value zero to 0 cells. Each CMUT cell was a square with a side length of $56 \mu \mathrm{m}$ and had a silicon plate thickness of $1.85 \mu \mathrm{m}$ with $400 \mathrm{~nm}$ aluminum on top. A gap of $410 \mathrm{~nm}$ silicon dioxide, $56 \mathrm{~nm}$ silicon nitride and $448 \mathrm{~nm}$ vacuum were employed to obtain a pull-in voltage of approximately $240 \mathrm{~V}$.

The fabrication was based on the direct wafer bonding technique and the LOCOS process (LOCal Oxidation of Silicon) inspired by Park et al. [40]. The nine-step process used four lithography masks and two SOI wafers. A complete description of the fabrication is found in [39]. The fabricated CMUT array after it was diced is shown in Fig. 3.

No backing was applied for the CMUT array, since it was calculated that the substrate ringing would not occur within the frequency band of the transducer itself [41], when a center frequency of $3 \mathrm{MHz}$ and a substrate thickness of $500 \mu \mathrm{m}$ were used.

\section{2. $P Z T$}

The PZT RCA array was designed and fabricated by Sound Technology, Inc. (State College, PA, USA) with materials and processes commonly used in commercial medical ultrasound 
Table 1: Transducer dimensional parameters

\begin{tabular}{|c|c|c|c|}
\hline Parameter & CMUT & PZT & Unit \\
\hline \multicolumn{4}{|l|}{ Array } \\
\hline Number of elements & $62+62$ & $62+62$ & - \\
\hline Number of apodization region electrodes & 4 & 4 & - \\
\hline Element pitch & 270 & 270 & $\mu \mathrm{m}$ \\
\hline Element width & 265 & 245 & $\mu \mathrm{m}$ \\
\hline Kerf & 5 & 25 & $\mu \mathrm{m}$ \\
\hline Element length & 24.84 & 24.84 & $\mathrm{~mm}$ \\
\hline Acoustic window thickness & 1.5 & 1.27 & $\mathrm{~mm}$ \\
\hline Acoustic window velocity & 1.0 & 1.0 & $\mathrm{~mm} / \mu \mathrm{s}$ \\
\hline Length of apodization regions & 4.05 & 4.05 & $\mathrm{~mm}$ \\
\hline Array outer dimensions (square) & 26.3 & 26.3 & $\mathrm{~mm}$ \\
\hline \multicolumn{4}{|l|}{ CMUT cell } \\
\hline Cell side length (square) & 56 & - & $\mu \mathrm{m}$ \\
\hline Kerf between cells & 7 & - & $\mu \mathrm{m}$ \\
\hline Plate thickness & 1.85 & - & $\mu \mathrm{m}$ \\
\hline Al electrode thickness & 400 & - & $\mathrm{nm}$ \\
\hline Vacuum gap height & 448 & - & $\mathrm{nm}$ \\
\hline Nitride thickness & 56 & - & $\mathrm{nm}$ \\
\hline Insulation oxide thickness & 410 & - & $\mathrm{nm}$ \\
\hline Post oxide thickness & 1346 & - & $\mathrm{nm}$ \\
\hline \multicolumn{4}{|l|}{ PZT element } \\
\hline PZT layer thickness & - & 500 & $\mu \mathrm{m}$ \\
\hline PZT volume fraction & - & 66 & $\%$ \\
\hline Electrode thickness & - & 640 & $\mathrm{~nm}$ \\
\hline Matching layer net thickness & - & 0.433 & $\mathrm{~mm}$ \\
\hline Layer 1 (Closest to transducer) & - & 0.190 & $\mathrm{~mm}$ \\
\hline Layer 2 & - & 0.125 & $\mathrm{~mm}$ \\
\hline Layer 3 & - & 0.118 & $\mathrm{~mm}$ \\
\hline Matching layer bulk acoustic impedance & - & - & MRayl \\
\hline Layer 1 (Closest to transducer) & - & 12 & MRayl \\
\hline Layer 2 & - & 4 & MRayl \\
\hline Layer 3 & - & 2.8 & MRayl \\
\hline Matching layers average velocity & - & 1.95 & $\mathrm{~mm} / \mu \mathrm{s}$ \\
\hline Backing round-trip attenuation at $f_{c} / 2$ & - & 100 & $\mathrm{~dB}$ \\
\hline
\end{tabular}

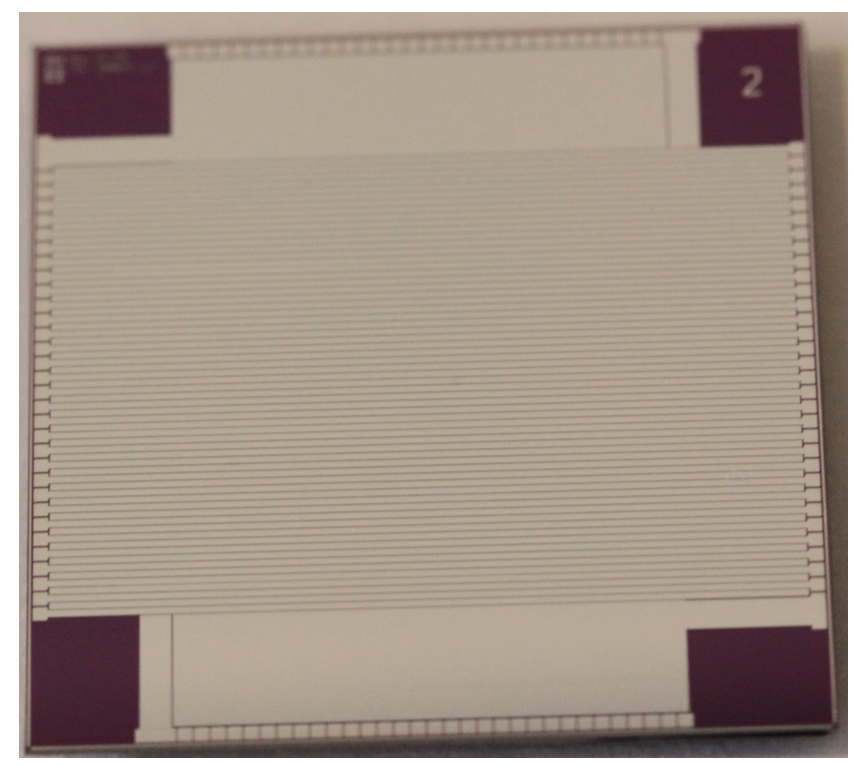

Figure 3: A fabricated CMUT array. Top elements are visible as thin lines at the center of the array. At the top and at the bottom, two large elements are seen, these are the two top apodization elements.

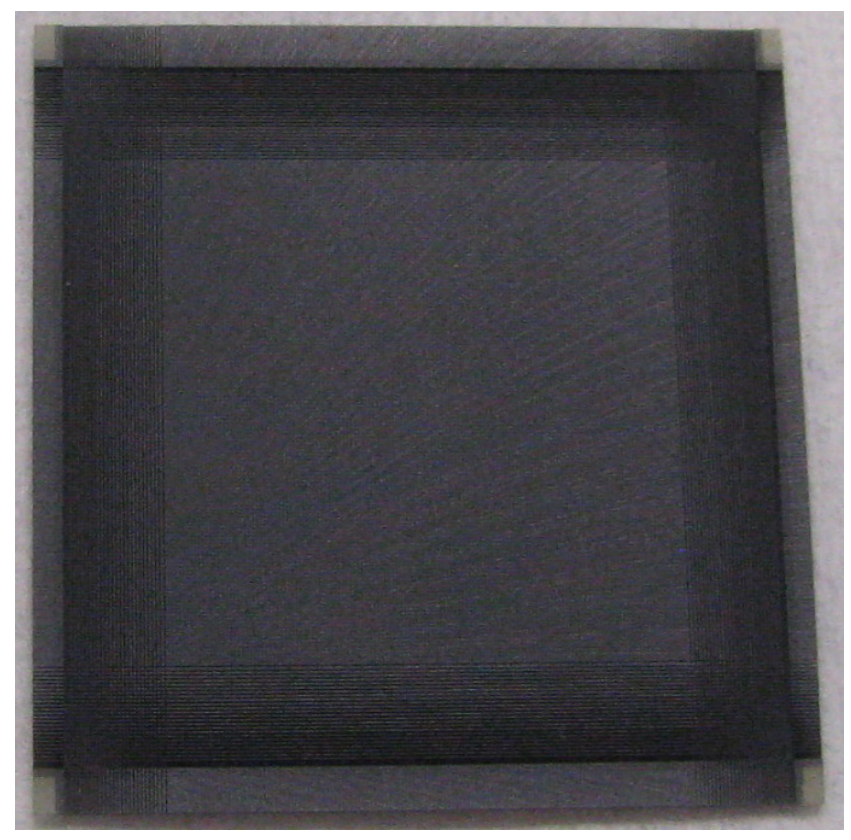

Figure 4: The PZT composite before plating. Color gradation towards the edges arise from the groove pattern (integrated apodization).

probes. The active layer consisted of a 1-3 composite of highdielectric PZT-5H (CTS 3257HD, CTS Corporation, Albuquerque, NM, USA) and epoxy. To achieve a favorable ceramic aspect ratio, the composite pitch was half the array pitch with a volume fraction of $66 \%$. The apodization region was integrated into the composite structure by patterning microgrooves on one surface [42].

The 1-3 composite was manufactured using conventional dice and fill technique, and was ground to obtain the desired thickness of $500 \mu \mathrm{m}$. Fig. 4 shows the PZT composite after dicing, and the color gradation towards the edge are from the groove pattern (integrated apodization). A $640 \mathrm{~nm}$ metal stack of titanium tungsten (TiW), nickel vanadium (NiV) and gold $\mathrm{Au}$, in that order, were sputtered on the top and bottom surfaces of the composite for electrodes. TiW functioned as an adhesion promoter for the $\mathrm{NiV}$ electrode material with gold as a passivation layer on top. Row and column elements were defined by scribing the top electrodes in one direction and the bottom electrodes in the orthogonal direction. This scribe was a shallow cut made with a dicing saw resulting in a kerf of $25 \mu \mathrm{m}$. Separately, a high-attenuation, mechanically rigid backing block and a stack of three quarter-wavelength matching layers were fabricated. The backing material was glued on to the backside with a thin electrical interconnect layer sandwiched between the composite and the backing block, and the matching layers were glued on to the front side of the composite. The matching layers were then diced, and the dicing was aligned with the electrode grid to reduce the mechanical coupling between adjacent elements. Fig. 5 shows two optical micrographs of the cross section of the PZT array after dicing of the matching layers. 


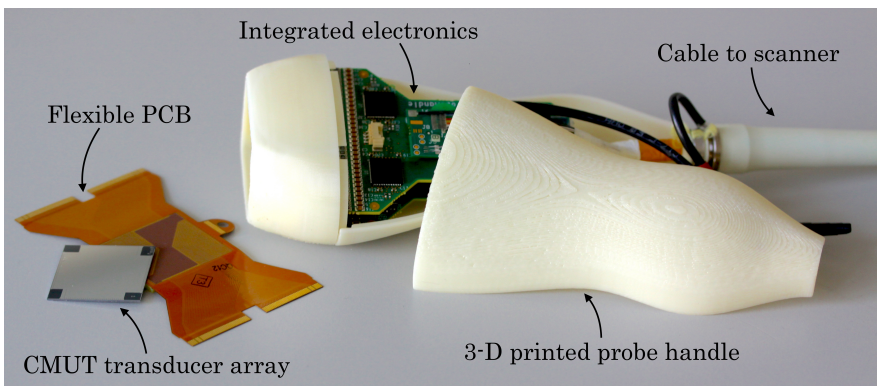

(a)

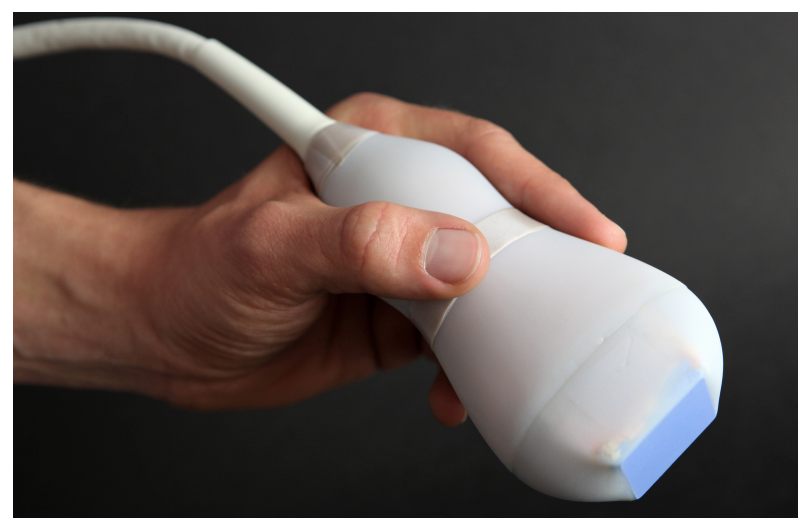

(b)

Figure 6: (a): The five main components of the probes with the CMUT transducer array. The components of the two probes are identical except for the transducers. (b): One of the fully assembled probes.

\section{Probe assembly}

The assembly of the two probes was almost identical after the fabrication of the arrays, and both were assembled at the facilities of Sound Technology Inc. (State College, PA, USA). The probes were composed of four parts in addition to the transducer array itself; see Fig. 6(a). They consisted of a flexible printed circuit board (PCB) for connecting the transducer to the electronics, the integrated electronics containing buffer amplifiers, a cable for connecting the probe to the scanner, and a 3-D printed probe handle.

\subsection{Assembly}

The arrays were mounted on flexible PCBs which were rigidly supported directly beneath the arrays. The PZT array connection to the PCB involved soldering, whereas the CMUT array used wire-bonding. Both arrays were mounted with the rows as top electrodes and columns as the bottom electrodes. A glob-top dam was applied around the CMUT array to ensure protection of the wire-bonds against mechanical stress, when pressing the probe against an object. Both arrays underwent an encapsulation step by applying an initial layer of planar room temperature vulcanizing (RTV) silicone and an electrical shield, an aluminizied polymer film $(12.5 \mu \mathrm{m}$ polypropylene with a sub-micron thick aluminum film). The glop-top dam determined the height of the initial layer of RTV silicone for the CMUT and for the PZT a shield standoff shim that was applied outside the active area. The same silicone material was used 
to fill the matching layer kerfs of the PZT array. Each array was then mounted into a 3-D printed plastic nose piece, after which a final layer of RTV silicone was applied and leveled to prevent a lens effect. Both arrays had flexible printed circuit interconnect components with identical connectors and pin maps, and they were attached to identical amplifier PCBs. These amplifier PCBs were attached to a 128-channel coaxial cable and wrapped with copper tape to provide an electromagnetic shield. The copper shield was connected to both the shielding foil applied to the front of the array and the shield of the coaxial cable, and hereby, also the reference ground of the scanner. Finally, the two 3-D printed plastic handle halves were glued to each other, the nose piece, and the strain relief to complete the probe assembly. One of the fully assembled probes is shown in Fig. 6(b).

\subsection{Electronics}

The interconnect electronics were the same as used by Christiansen et al. [36], however the MAX4805A amplifier (Maxim Integrated, San Jose, CA, USA) had been exchanged with the ADHV1301 amplifier (Analog Devices, Norwood, Ma, USA). The two electronics PCBs in the probe contained preamplifiers with a $0 \mathrm{~dB}$ voltage gain, and they worked as high impedance buffer amplifiers that remove the electrical load of the cable on the arrays. The PCBs also contained passive high pass filters for separating the $\mathrm{DC}$ bias voltage from the $\mathrm{AC}$ voltage signals. Electronics were designed to allow all elements to be used interchangeably as either transmitters or receivers. Both probes were equipped with the exact same integrated electronics, but no bias voltage was supplied to the PZT probe.

The ADHV1301 is an application specific standard product (ASSP) integrated circuit with a similar performance to the MAX4805A, i.e. a high-voltage-protected, low-noise operational amplifier designed to be used as an amplifier for in-probe buffering and amplification. The device has 16 input channels, a $30 \mathrm{MHz}-3 \mathrm{~dB}$ bandwidth and the small-signal output impedance of amplifiers of $18 \Omega$ is suitable for matching the cable impedance. The voltage and current noise is $1.7 \mathrm{nV} / \sqrt{\mathrm{Hz}}$ and $2.1 \mathrm{pA} / \sqrt{\mathrm{Hz}}$, respectively. The high voltage protection circuit is activated for voltages larger than $1000 \mathrm{mV}_{\mathrm{pp}}$ and the maximum allowed voltage is $\pm 125 \mathrm{~V}$. The recovery time after a transmit burst is less than $800 \mathrm{~ns}$. Unfortunately, the ADHV1301 has been discontinued during the time of this study, and no description is available to use as a reference.

\section{Measurement set-up}

Characterization of the two developed RCA probes was performed using five different measurement set-ups. The first measurement was dedicated to measuring the element capacitance and the second to ascertain the two-way impulse response. The last three measurements were performed using the experimental ultrasound system, SARUS [38], one to obtain the emitted pressure, the second was a pulse-echo measurement, and the third was to assess the acoustical crosstalk. Fig. 7 shows a schematic drawing of the three acoustic set-ups described in Sections 4.24.4. The measurement set-ups are introduced below.

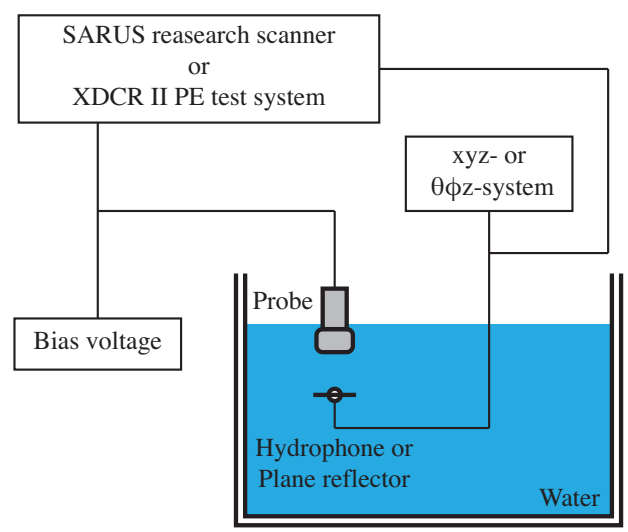

Figure 7: Schematic of the three acoustic set-ups described in Sections 4.2-4.4. The sole of each probes was placed in water in front of a hydrophone/plane reflector, which was controlled by a $x y z / \theta \phi z$-system for alignment. The set-up described in Section 4.2 uses the XCDR II Pulse Echo Test System, the $\theta \phi z$ system, and the plane reflector. The set-up described in Section 4.3 uses the SARUS research scanner [43], the xyz-system, and the hydrophone. The set-up described in Section 4.4 uses the SARUS research scanner [43], no alignment system, and the plane reflector.

\subsection{Capacitance}

The element capacitances were measured using a HP 4263B LCR meter (Hewlett-Packard Company, CA, USA). Because the amplifiers in the probe handle had protection circuitry that was incompatible with the LCR meter, the measurement was performed before the final assembly. Transducers were connected to a test cable, which was plugged into a multiplexer box connected to the LCR meter. All elements except the test element were shorted to ground. To eliminate the parasitic capacitance and inductance of the set-up, all channels of the multiplexer and the test cable were measured independently.

\subsection{Impulse Response}

The pulse-echo response of each element was measured using an XCDR II Pulse Echo Test System, by emitting and receiving with one element at a time against a planar stainless steel reflector. The planar reflector was placed in $37^{\circ} \mathrm{C}$ deionized (DI) water $25 \mathrm{~mm}$ from the face of the probe. With the available set-up, the elements were actuated with a square unipolar pulse with a duration of $100 \mathrm{~ns}$ for the PZT and $150 \mathrm{~ns}$ for the CMUT and with an amplitude of $50 \mathrm{~V}$. The CMUT elements were biased at $200 \mathrm{Vdc}$. The system was set to sample at a sampling frequency of $500 \mathrm{MHz}$. The received signal was de-convolved with the excitation pulse to yield the two-way element-element impulse response.

From the impulse response and the corresponding spectrum, the center frequency, the bandwidth, and the phase delay of each element were found.

\subsection{Hydrophone}

The pressure was measured using an HGL-0400 hydrophone connected to an AC-2010 pre-amplifier (Onda Corporation, CA, USA). The hydrophone was placed in front of the transducer surface and scanned over each element using the position 
system of the intensity measurement AIMS-3 (Onda Corporation, CA, USA), while transmitting a $3 \mathrm{MHz}$, 4-cycle sinusoidal signal on the element being measured. An amplitude of $75 \mathrm{Vac}$ was used and the CMUT probe was biased with $200 \mathrm{Vdc}$. The pressure was recorded at $5.8 \mathrm{~mm}$ and $5.9 \mathrm{~mm}$ for the PZT and CMUT, respectively.

\subsection{Pulse-Echo and Crosstalk}

A plane stainless steel reflector was positioned in a water tank at a distance of $7.3 \mathrm{~cm}$ from, and parallel to, the transducer surface of the probe being characterized. The transmit signals were generated using the experimental ultrasound system, SARUS [38], which also recorded the received signals. Twenty realizations of a $3 \mathrm{MHz}, 4$-cycle sinusoidal excitation pulse were transmitted on one element at a time and received on all elements, both rows and columns. The 20 realizations were averaged to minimize the noise. The system was set to sample at a sampling frequency of $70 \mathrm{MHz}$, down to a depth of $10 \mathrm{~cm}$. A second measurement was performed using the same set-up, but without the planar reflector, to assess the acoustical crosstalk.

\section{Transducer characterization}

This section describes the characterization of the two probes based on the measurements introduced in the previous section. The performance of the two probes was evaluated concurrently and is described below. Table 2 summarizes the main results of the characterization, allowing easy location of specific parameters.

\subsection{Capacitance}

The capacitance measured using the LCR meter also included a contribution from the multiplexer and the test cable. To isolate the element capacitances from the LCR measurements, the independent measurements of all the channels of the multiplexer and the test cable were subtracted from the overall measurements (multiplexer + test cable + array). The element capacitances of both probes are shown in Fig. 8. Some of the element capacitances appear to be missing; this is due to an artifact of the measurement set-up. A high series resistance resulted in a faulty detection of the capacitance and was, therefore, omitted. This might be the effect of inferior connections to the specific elements. The mean capacitance of the PZT probe was $301.7 \pm 2.2 \mathrm{pF}$ and the mean of the rows and columns of the CMUT probe was $339.4 \pm 0.8 \mathrm{pF}$ and $136 \pm 1.4 \mathrm{pF}$, respectively. The low standard deviation reflected the robust control of the fabrication methods.

The bottom elements (1-62) of the CMUT probe had a higher capacitance than the top elements (63-124). This is due to a capacitive coupling to the substrate of the bottom SOI wafer $[31,36,39,44]$. The capacitance of the buried oxide (BOX), $C_{\mathrm{BOX}}$, was approximately $230 \mathrm{pF}$, in agreement with the $1 \mu \mathrm{m}$ silicon oxide between the bottom electrode and the substrate, and the dimensions of the electrode.


Figure 8: Capacitance across the array elements of both probes. Element number from 1-62 corresponds to the columns and 63-124 to the rows.

\subsection{Impulse response}

The signals received from the impulse response measurements, described in Section 4.2, were de-convolved with the excitation pulse to yield the two-way element-element impulse response. Fig. 9 shows the average two-way element-element impulse response and the associated envelope of the CMUT (a) and the PZT probe (b). The solid line represents the impulse response and the dashed line the envelope with black and orange representing the rows and columns, respectively.

Two extra lobes after the main lobe, around $-30 \mathrm{~dB}$, were observed for the CMUT at starting times of $3.2 \mu \mathrm{s}$ and $4.7 \mu \mathrm{s}$. These extra lobes also existed for the PZT probe, but were not as easily recognized as they coincided with the ringing of the transducer itself. The time difference between the two lobes was $1.5 \mu$ s corresponding to the time difference between the main lobe and the first secondary lobe. This suggested that these extra lobes originate from reflections within the probes. Both arrays were encapsulated in RTV silicone, which had an acoustic velocity of $1.0 \mathrm{~mm} / \mu \mathrm{s}$, indicating that a reflecting structure was present at a distance of $0.75 \mathrm{~mm}$ from the transducer surfaces. This corresponded to the shielding foils that covered the arrays. The envelope shows that the internal reflections of the probe were roughly $-30 \mathrm{~dB}$, which is an acceptable limit for ultrasound transducers.

The received signals of the columns of the CMUT probe were observed to be roughly half of the signal measured for the rows. This was due to the capacitive coupling to the substrate. It should, however, be noted that even though the signal amplitude differed between the rows and columns, the shape of the envelopes were identical.

The frequency spectra are calculated by computing the Fourier transform of the impulse response and are shown in Fig. 10. From the spectrum of the impulse response, the center frequency, and bandwidth for each element are found and presented in the following.

\subsection{Center frequency}

The center frequency was calculated as a weighted mean of the frequencies present in the received signal as: 
Table 2: Main results of the characterization of the transducers

\begin{tabular}{|c|c|c|c|c|c|c|}
\hline \multirow{2}{*}{ Parameter } & \multicolumn{3}{|c|}{ CMUT } & \multicolumn{3}{|c|}{ PZT } \\
\hline & Row & Column & Mean & Row & Column & Mean \\
\hline Capacitance $[\mathrm{pF}]$ & $339.4 \pm 0.8$ & $136.1 \pm 1.4$ & $239.6 \pm 102.1$ & $301.6 \pm 2.6$ & $301.8 \pm 1.7$ & $301.7 \pm 2.2$ \\
\hline Center frequency $[\mathrm{MHz}]$ & $2.97 \pm 0.07$ & $3.05 \pm 0.09$ & $3.01 \pm 0.09$ & $2.98 \pm 0.05$ & $3.00 \pm 0.05$ & $2.99 \pm 0.05$ \\
\hline Bandwidth [\%] & $111 \pm 3$ & $106 \pm 4$ & $109 \pm 4$ & $79 \pm 3$ & $81 \pm 2$ & $78 \pm 3$ \\
\hline Phase delay $\left[{ }^{\circ}\right]$ & $0 \pm 5.0$ & $0 \pm 3.1$ & $0 \pm 4.5$ & $0 \pm 11$ & $0 \pm 13$ & $0 \pm 12$ \\
\hline Surface Pressure $[\mathrm{MPa}]$ & $0.56 \pm 0.05$ & $0.54 \pm 0.07$ & $0.55 \pm 0.06$ & $1.66 \pm 0.10$ & $1.71 \pm 0.06$ & $1.68 \pm 0.09$ \\
\hline Sensitivity $[\mu \mathrm{V} / \mathrm{Pa}]$ & $12.9 \pm 0.7$ & $4.3 \pm 0.7$ & $8.5 \pm 4.4$ & $13.7 \pm 2.1$ & $15.1 \pm 1.3$ & $14.4 \pm 1.9$ \\
\hline Insertion loss [dB] & $-26.4 \pm 0.9$ & $-36.5 \pm 2.5$ & $-31.5 \pm 5.4$ & $-16.6 \pm 1.7$ & $-15.3 \pm 0.8$ & $-15.9 \pm 1.5$ \\
\hline Nearest neighbor crosstalk [dB] & $-30.5 \pm 0.8$ & $-26.3 \pm 1.4$ & $-28.4 \pm 2.4$ & $-28.3 \pm 1.2$ & $-31.8 \pm 1.5$ & $-30.0 \pm 2.2$ \\
\hline Transmit-receive elements crosstalk [dB] & $-39.9 \pm 0.2$ & $-40.2 \pm 0.6$ & $-40.0 \pm 0.4$ & $-53.6 \pm 0.8$ & $-53.8 \pm 0.9$ & $-53.7 \pm 0.9$ \\
\hline
\end{tabular}



(a)

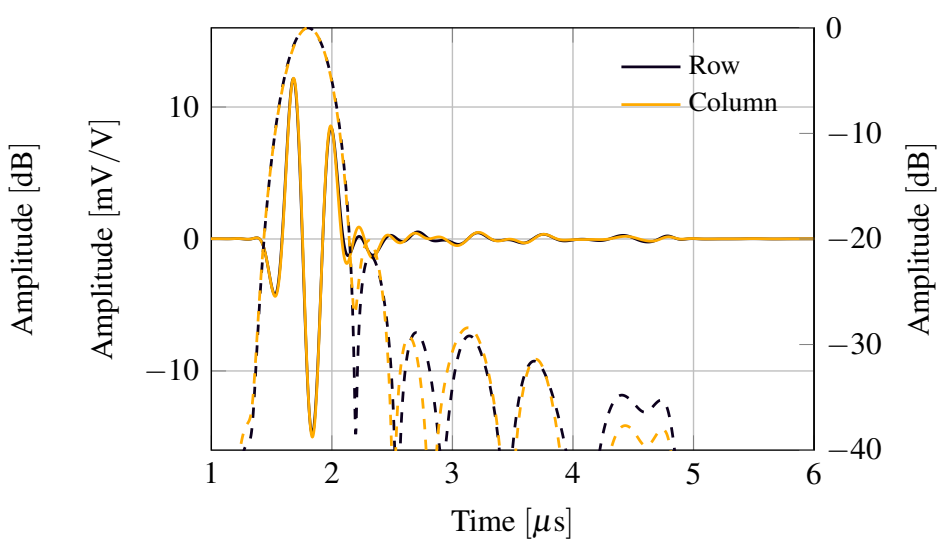

(b)

Figure 9: Average impulse response (solid) and normalized envelope (dashed) of the probe elements (a): CMUT. (b): PZT.

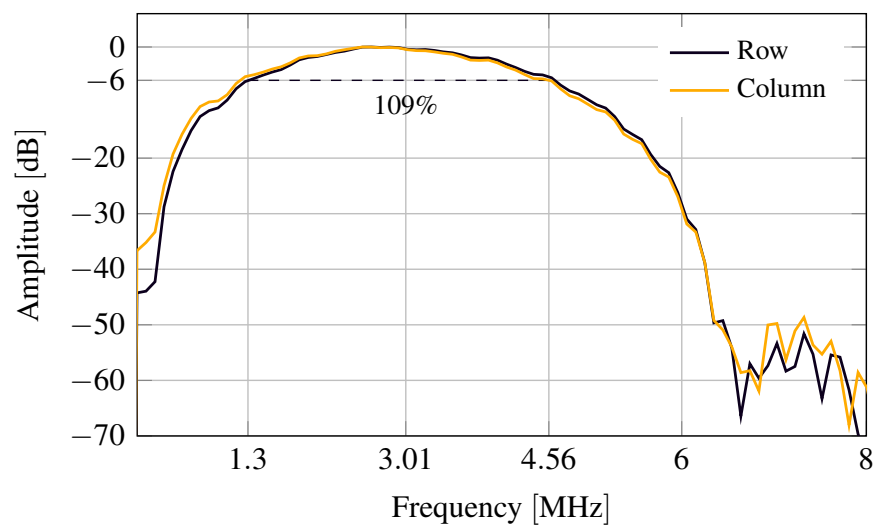

(a)

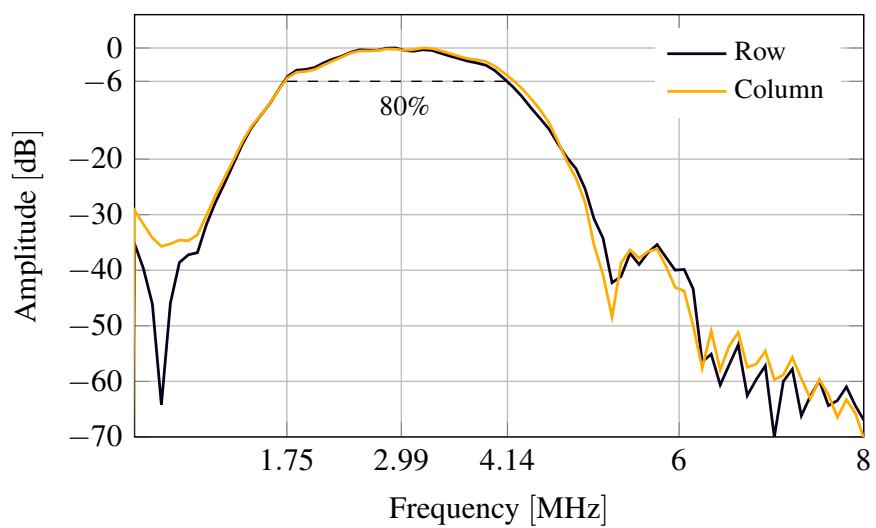

(b)

Figure 10: The mean impulse response spectra are shown for the rows and columns for both probes. The center frequency and the fractional bandwidth are indicated on the plot. (a): CMUT. (b): PZT. 


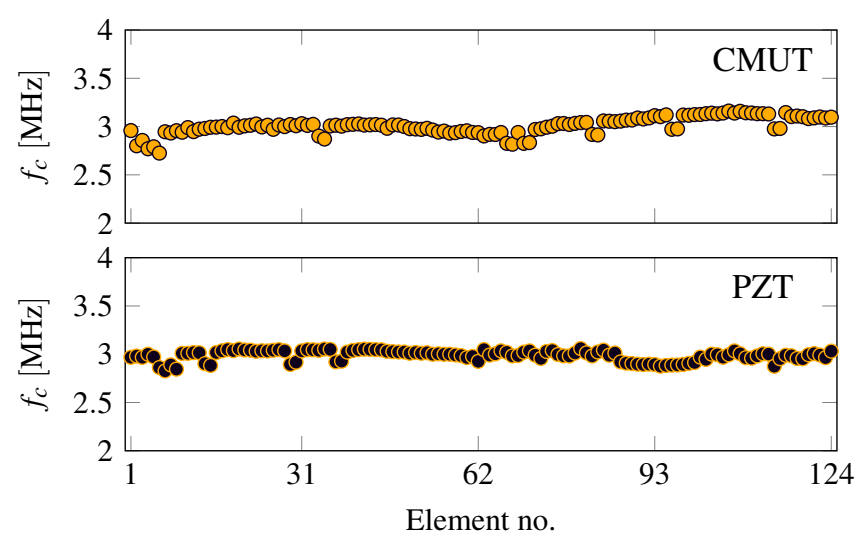

Figure 11: Center frequency across the array elements of both probes. The center frequency was calculated as a weighted mean of the frequencies present in the signal. Element number from 1-62 corresponded to the columns and 63-124 to the rows.

$$
f_{c}=\frac{\sum_{i=0}^{N / 2} S\left(i f_{s} / N\right) \cdot i f_{s} / N}{\sum_{i=0}^{N / 2} S\left(i f_{s} / N\right)}
$$

where $N$ is the number of frequency bins in the two-sided spectrum.

Fig. 11 shows the uniformity of the center frequency across the arrays. Both probes had a center frequency of $3 \mathrm{MHz}$ as they were designed for, and only a small smooth variation across the arrays was observed. This smooth variation indicated that the variations were mostly caused by non-uniformities of the silicon plates of the CMUT probe, and thickness-variations of the piezoelectric material of the PZT probe.

\subsection{Bandwidth}

The $-6 \mathrm{~dB}$ bandwidth was determined from the difference in frequency between the $-6 \mathrm{~dB}$ points in the frequency spectrum. Mean bandwidths of $3.26 \pm 0.02 \mathrm{MHz}$ and $2.39 \pm 0.02 \mathrm{MHz}$ were found for the CMUT and the PZT probes, respectively. The fractional bandwidths were calculated from the bandwidth relative to the weighted center frequency, and a mean value of $109 \%$ and $80 \%$ were found for the CMUT and the PZT, respectively. The uniformity across the array for both probes is shown in Fig. 12. The probes had high uniformity with a standard deviation of the fractional bandwidth of $4 \%$ for the CMUT probe and $3 \%$ for the PZT probe.

\subsection{Phase delay}

The phase delay was found by cross-correlating the impulse response for each element with the mean impulse response and interpolating to find the lag of the maximum of the crosscorrelation. Correction for any linear slope due to misalignment between the transducer and the plane reflector was done, and the mean was subtracted. The phase delay was then calculated by dividing the time delay with the time it takes the wave to travel

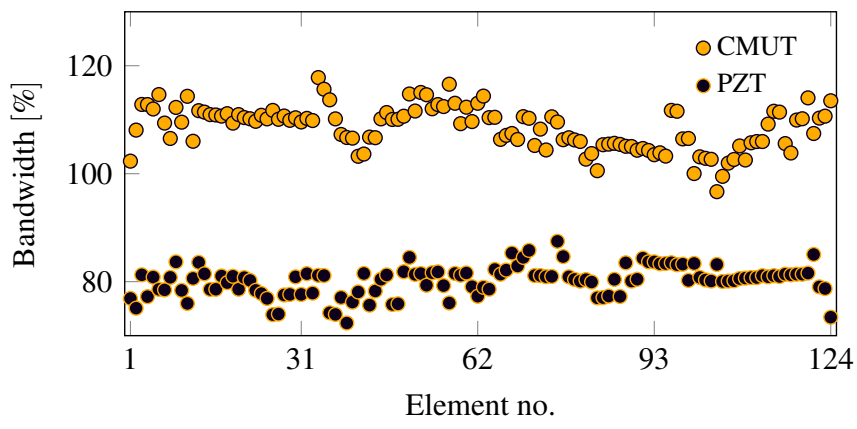

Figure 12: Bandwidth across the array elements of both probes. Element number from 1-62 corresponded to the columns and 63-124 to the rows.

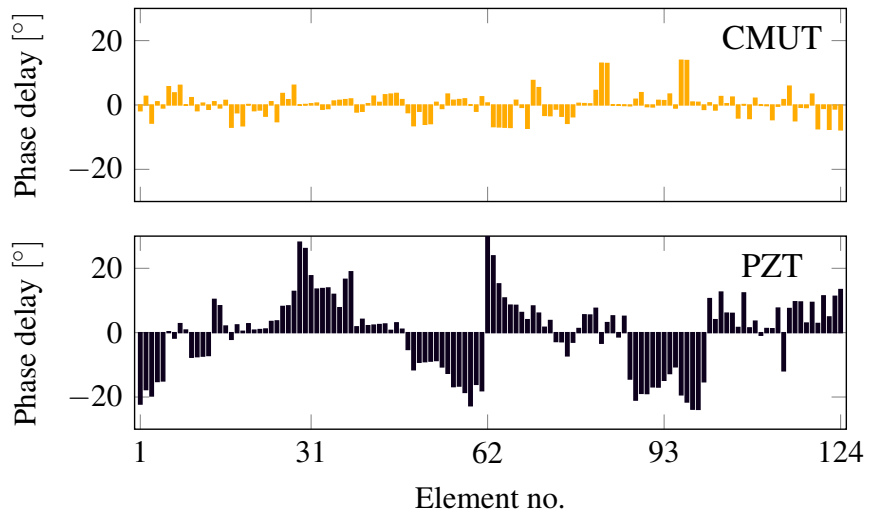

Figure 13: Phase delay across the array elements of both probes. Element number from 1-62 corresponded to the columns and 63-124 to the rows.

one wavelength at $3 \mathrm{MHz}$, and multiplying it by $360^{\circ}$, to obtain the phase delay in degrees. Fig. 13 shows the phase delay across the array for the CMUT and the PZT in top and bottom, respectively.

No curvature was seen of the CMUT, however the PZT was observed to curve. The bottom/column elements phase delays were seen to have a concave profile, whereas the top/row elements had a convex profile. This saddle shape was believed to originate from stress build up during the assembly.

\subsection{Surface pressure}

The surface pressure was derived from the hydrophone measurement with the set-up described in section 4.3. The recorded pressure was compensated to find the emitted pressure at the transducer surface. This compensation factor was calculated by simulating a single element in Field II $[45,46]$. The element was set to emit a $3 \mathrm{MHz}$, 4-cycle sinusoidal wave, and the pressure magnitude relative to the pressure magnitude at the element surface was simulated. The compensation factor for the PZT and CMUT were 9.14 and 8.83, respectively. The difference was caused by the different locations of the hydrophone during the two measurements. The surface pressure across the arrays is shown in Fig. 14. The mean values for the CMUT and PZT were $0.55 \pm 0.06 \mathrm{MPa}$ and $1.68 \pm 0.09 \mathrm{MPa}$, respectively. 


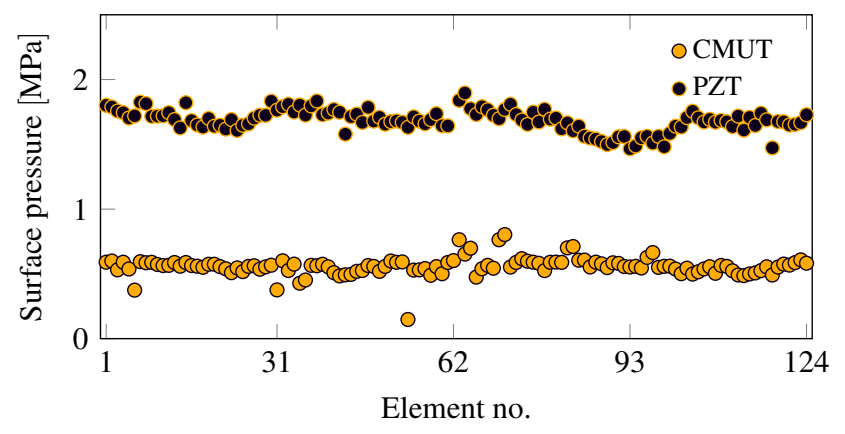

Figure 14: Surface pressure across the array elements of both probes. Element number from 1-62 corresponded to the columns and 63-124 to the rows.

Notice that there was no difference between the pressures emitted by the CMUT columns (elements 1-62) and the CMUT rows (elements 63-124). One would have expected a lower emitted pressure from the columns due to the increased parasitic capacitance, hence a lower coupling coefficient. This was, however, not the case, since the power source during the emission was not limited in the amount of energy it could supply to the transducer.

\subsection{Receive sensitivity}

The receive sensitivity was calculated by combining the result from hydrophone measurement (Section 4.3) with the result from pulse-echo measurement (Section 4.4). The receive sensitivity of the transducers was found by dividing the received voltage signal after a pulse-echo event with the incident pressure. The incident pressure was deduced using the pressure measured from the hydrophone set-up. The pressure drop was compensated using the same Field II model described in the previous section. Besides compensating the incident pressure for the diffraction loss, the non-ideality of the plane reflector is also compensated for. The reflection coefficient for a normal incident wave was solely determined from the acoustic impedance discontinuity in the transmission medium. In water, the reflection coefficient for a stainless steel reflector is 0.93 [47]. The receive sensitivity for each element across the two probes is shown in Fig. 15. The mean values of the CMUT and the PZT probe were $8.5 \pm 4.4 \mu \mathrm{V} / \mathrm{Pa}$ and $14.4 \pm 1.9 \mu \mathrm{V} / \mathrm{Pa}$, respectively.

The sensitivity of the CMUT bottom/column elements was $67 \%$ lower than the top/row elements. This was due to the capacitive coupling to the substrate discussed in Section 5.1. The two parallel coupled capacitors $\left(C_{\mathrm{CMUT}}\right.$ and $C_{\mathrm{BOX}}$ act as a current divider, resulting in the lower detected voltage (lower sensitivity). When imaging with RCA arrays, either the rows or columns were used as transmitters and the orthogonal elements as receivers. Choosing the bottom/column elements as the emitters and the top/row elements as receivers, the imaging was not affected by the lower sensitivity. However, determining 3-D vector flow might have been affected since the sequence used both rows and columns as emitters and receivers [48, 49].

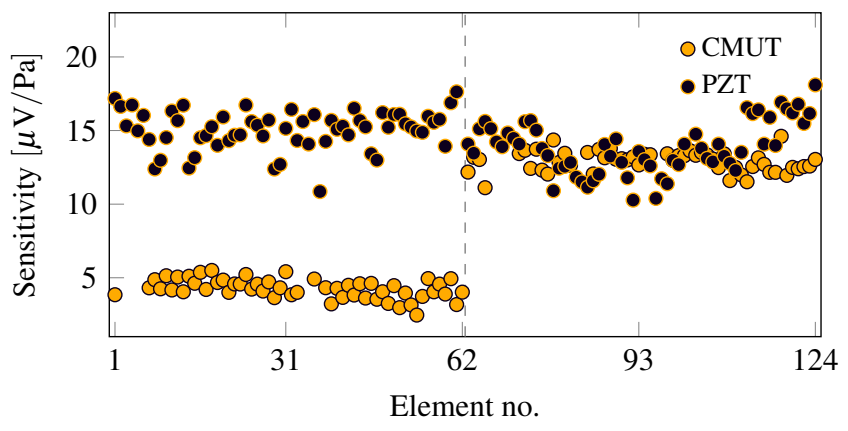

Figure 15: Sensitivity across the array elements of both probes. Element number from 1-62 corresponded to the columns and 63-124 to the rows.

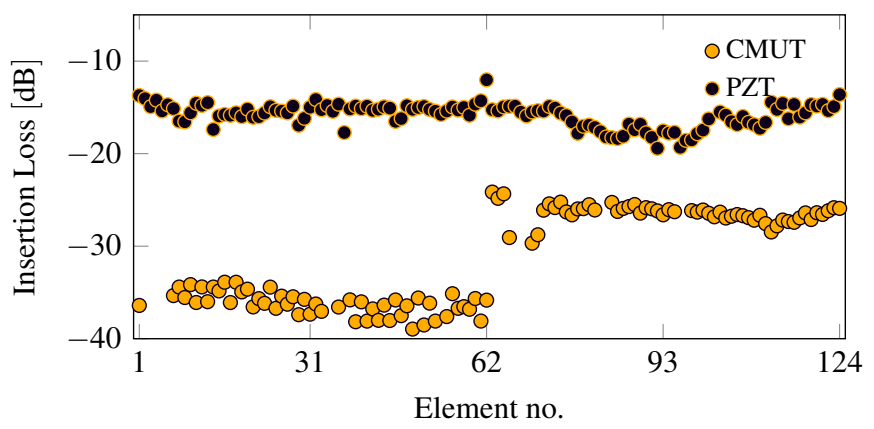

Figure 16: Insertion loss across the array elements of both probes. Element number from 1-62 corresponds to the columns and 63-124 to the rows.

\subsection{Insertion loss}

The insertion loss is the loss of signal power resulting from the "insertion" of the device and is a measure of the overall round-trip efficiency (round-trip loss of signal power). It was calculated as the ratio of voltage received by an element after a pulse echo event, $V_{\mathrm{R}}$, to the transmit voltage used to excite the element, $V_{\mathrm{T}}$ [47]. The received signal was compensated to exclude the loss of signal due to diffraction and the non-ideality of the planar reflector. A log-compression of the ratio yielded the insertion loss in $\mathrm{dB}$ :

$$
\text { Insertion loss }(\mathrm{dB})=20 \log _{10} \frac{V_{\mathrm{R}}}{V_{\mathrm{T}}} .
$$

The insertion loss across both arrays is shown in Fig. 16. The mean value all the elements of the PZT probe was $-15.9 \pm$ $1.5 \mathrm{~dB}$ and the mean values of the rows and columns of the CMUT probe were $-26.4 \pm 0.9 \mathrm{~dB}$ and $-36.5 \pm 2.5 \mathrm{~dB}$, respectively. Since the receive sensitivities of the two arrays were similar, the lower insertion loss of the CMUT probe was mainly an effect of the lower transduction efficiency from the mechanical domain to the acoustic domain i.e. due to the lower surface pressure. The insertion loss was mainly a parameter used in the next section when estimating the acoustical crosstalk.

\subsection{Acoustical crosstalk}

The second measurement set-up described in Section 4.4 was used for evaluating the crosstalk. The first $3 \mu$ s of the received data were disregarded because the receivers were saturated due 


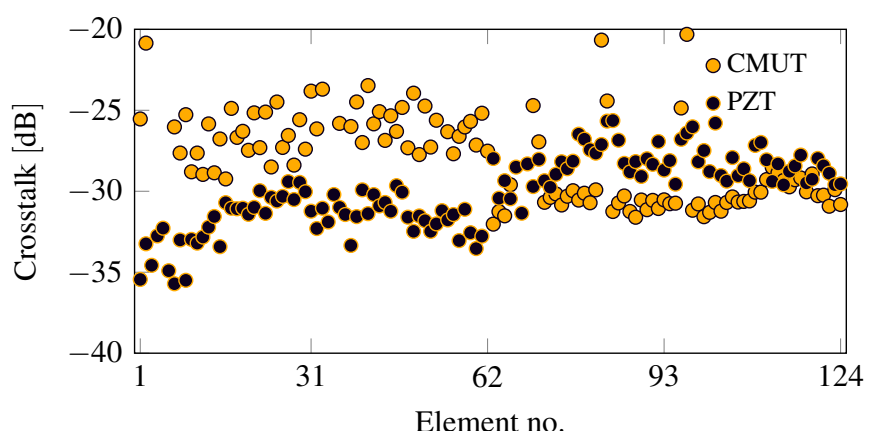

Figure 17: Nearest neighbor crosstalk across the array elements of both probes. Element number from 1-62 corresponds to the columns and 63-124 to the rows.

to the transmit pulse (electrical crosstalk) and the ring-down of the electronics.

Two different types of acoustical crosstalk can be evaluated when using RCA arrays: Nearest neighbor crosstalk and transmit-to-receive crosstalk [50]. Emitting with one element at the time and extracting the maximum of the signal from its neighbor yielded the nearest neighbor crosstalk for every element. To provide a relative measure, the signal was normalized to the transmit voltage after the latter was corrected for the insertion loss of the emitting element. The insertion loss is reported in Section 5.8. The correction corresponded to a normalization of the neighbor's signal to the signal that the emitting element would have received, if the transmitted pulse were reflected right at the transducer surface and subsequently received by the emitting element. Thus, it yielded the relative acoustical coupling from one element to its neighbor. The nearest neighbor crosstalk across the probes is shown in Fig. 17 and the mean values were $-28.4 \pm 2.4 \mathrm{~dB}$ and $-30.0 \pm 2.2 \mathrm{~dB}$ for the CMUT and PZT probe, respectively. The nearest neighbor crosstalk of the CMUT was roughly $5 \mathrm{~dB}$ lower than earlier reported values in literature $[50,51]$. The lower crosstalk could be due to the RTV silicone on top of the array. The amount of crosstalk for the PZT probe was in the limit of what is usually accepted for ultrasound probes. Ideally for phased arrays, one would dice into the piezoelectric ceramic during fabrication and fill it up with the RTV silicone to reduce the crosstalk. This was, however, not possible with RCA arrays.

To provide a measure of the crosstalk in an imaging set-up, the transmit-to-receive crosstalk was estimated. This was calculated as the average of the maximum signal received on all elements orthogonal to the emitting element. The average was normalized to the transmit voltage of the emitting element and corrected for the insertion loss. The transmit-to-receive elements crosstalk is shown in Fig. 18 for both arrays and the mean values were $-40.0 \pm 0.5 \mathrm{~dB}$ and $-53.7 \pm 0.9 \mathrm{~dB}$ for the CMUT and PZT probe, respectively. This was consistent with results in literature for the CMUT [50] and has not been previously reported for PZT RCA arrays.

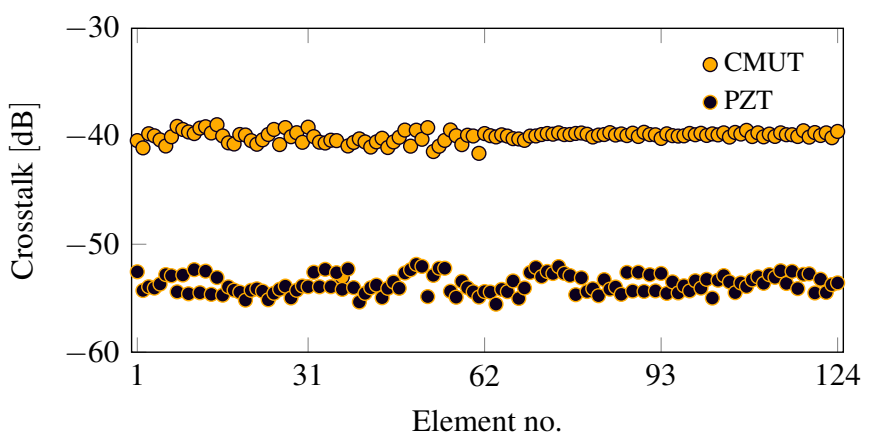

Figure 18: Transmit-receive elements crosstalk across the array elements of both probes. Element number from 1-62 corresponds to the columns and 63124 to the rows.

\section{Discussion}

We have presented the development and transducer performance of two RCA probes for real-time volumetric imaging based on two competing technologies: CMUT and PZT. The central part of this paper has been to characterize the two developed transducers. The characterization should not be seen as a comparison of the two technologies, but as a display of the capabilities of the row-column-addressing scheme using these two technologies. However, since these two technologies are evaluated next to each other, one cannot avoid comparing them. The strengths and weaknesses of the emerging technology, CMUT, will therefore be discussed in relation to the traditional technology, PZT.

One of the most highlighted advantages of the CMUT is its higher bandwidth relative to the PZT technology. The mean $-6 \mathrm{~dB}$ bandwidth was 29 percentage points higher for the CMUT probe compared to the PZT. The higher bandwidth is caused by the CMUT acting as an overdamped system, due to the low impedance of the vibrating plate in immersion. The high bandwidth and the corresponding short pulse length resulted in an improved axial resolution. It can also be beneficial in non-linear imaging.

A current limitation of the CMUT technology is the lower emitted pressure. This is a result of the low inertia of the plate (thin plate, low mass). The surface pressure of the PZT probe was consistently 3 times higher than the CMUT probe. Contrary to expectations, the mean receive sensitivity of the PZT probe was $11 \%$ higher than the top/row elements of the CMUT probe. Optimizing the structure, plate design, layout, and driving conditions can improve the sensitivity of the CMUT array. Packing the cells closer will increase the effective area. The CMUT structure can be designed to decrease the parallel parasitic capacitance originating from the bonding area between the cells. This could be implemented by incorporating a bump in the cavity as introduced by Park et al. [52]. This facilitates the possibility of having a high ratio of post oxide thickness to gap height. Improving the driving conditions also makes it possible to increase performance of the CMUT probe. The bias voltage is closely related to the electro-mechanical coupling coefficient describing the efficiency at which the mechanical energy (vibra- 
tions) is converted to electrical energy and vice versa. The coupling coefficient approaches unity at the pull-in voltage [53]. Increasing the bias voltage will result in a higher receive sensitivity and emitted pressure [54]. The bias voltage of the probe in this study was limited to $200 \mathrm{~V}$ because of the integrated electronics. As a result, the probe is operated at a maximum of $83 \%$ of the pull-in voltage. The optimal driving conditions and the gain hereof will be investigated in future research. If both the emitted pressure and the receive sensitivity are taken into account, one will expect the penetration depth of the PZT probe to be 3.4 times higher compared to the CMUT probe at these driving conditions. A potential way of increasing the pressure, and hence the penetration depth, is by emitting with more than one element. However, the pressure generated by the transducer is usually limited by both the mechanical index and the temperature of the probe itself [55].

An advantage of the RCA scheme is that the crosstalk in the imaging configuration, transmit-to-receive element crosstalk, is significantly lower than the nearest element crosstalk. This is due to the orthogonal orientation of the transmit- and receiveelements, as explained by Christiansen et al. [50]. There was, however, a significant difference of $14 \mathrm{~dB}$ between transmit-toreceive element crosstalk of the CMUT and PZT array, which is attributed to the electronic ring-down of the system. Both types of crosstalk are visualized in Fig. 19, where element number 1 is excited, and all elements record the received signal. The recorded signals were normalized with the insertion loss of the corresponding receiving element as explained in section 5.9. The 1-D configuration shows the signals received from the elements parallel to the emitting element, and $\mathrm{RC}$ configuration shows the signals received of the orthogonal elements. For both configurations the ring-down is observed. In the 1-D configuration the crosstalk was observed on top of the ring-down signal, which were seen as high velocity waves starting in the upper left corner. In the RC configuration, the crosstalk was not observed due to the ring-down of the electronics, which was of similar magnitude. The transmit-to-receive element crosstalk reported of both arrays is therefore not the true crosstalk, but a measure of the maximum crosstalk. Since the insertion loss was $14 \mathrm{~dB}$ lower on average for the CMUT array and the electronic ring-down was of similar magnitude, the $14 \mathrm{~dB}$ higher maximum crosstalk is expected.

The imaging performance of the two probes is investigated in another paper [56].

\section{Conclusion}

This paper presented the development and characterization of two 62+62 RCA ultrasound probes based on CMUT and on PZT technology. The objective of the paper has been to show the capabilities of the RCA transducer implemented using the two specific technologies. Both transducers have integrated apodization to reduce ghost echoes and are designed with similar acoustical features. They were designed to be used with a commercial scanner made for conventional 2-D imaging. Due to the low channel count of the RCA probes, the probes and scanner can be directly interfaced. A solution with a flexible
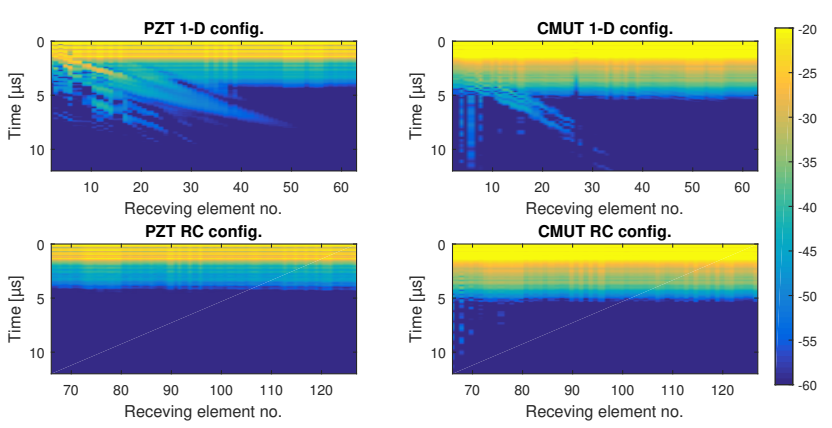

Figure 19: Data acquired using the set-up described in Section 4.4. Time zero corresponds to the onset of the transmit pulse. Element 1 is used as the emitter and all elements are used to receive. The 1-D configuration shows the signals received from the elements parallel to the emitting element, and the RC configuration shows the signals received on the orthogonal element.

mounting PCB and two rigid amplifier PCBs was used to mount the array and interface it to the scanner cable via buffer amplifiers. The array and electronics were electrically shielded with a metal foil, and the array was covered with a silicone coating before the entire probe was encapsulated in a 3-D printed handle. The reliability and performance of the probes were assessed through electrical and acoustical measurements. Four different measurement set-ups were used and the probes' electrical capacitances, center frequencies, bandwidths, phase delays, surface pressures, receive sensitivities, insertion loss, and acoustical crosstalks were evaluated. The weighted center frequencies were exactly $3.0 \mathrm{MHz}$ for both probes, as designed. The $-6 \mathrm{~dB}$ fractional bandwidth was 29 percentage point higher for the CMUT probe than the PZT. The surface pressure of the PZT probe was a factor 3 times higher relative to the CMUT probe. The authors emphasize that the driving conditions of the CMUT probe was limited by the integrated electronics in the probe handle, which could otherwise have improved its performance.

\section{Acknowledgments}

The authors would like to thank Daniel Bøjle (DELTA Dansk Elektonik, Lys \& Akustik, Hørsholm Denmark) for wirebonding and glop-topping of the CMUT array, and Michael Berkheimer (Sound Technology Inc., State College, PA, USA) for designing the flexible printed circuit board. This work was financially supported by the Danish National Advanced Technology Foundation (82-2012-4) and by BK Ultrasound, Herlev, Denmark.

\section{References}

[1] O. T. von Ramm, S. W. Smith, H. G. Pavy, High speed ultrasound volumetric imaging system - Part II: Parallel processing and image display, IEEE Trans. Ultrason., Ferroelec., Freq. Contr. 38 (1991) 109-115.

[2] D. H. Turnbull, F. S. Foster, Beam steering with pulsed two-dimensional transducer arrays, IEEE Trans. Ultrason., Ferroelec., Freq. Contr. 38 (4) (1991) 320-333.

[3] S. W. Smith, H. G. Pavy, O. T. von Ramm, High speed ultrasound volumetric imaging system - Part I: Transducer design and beam steering, IEEE Trans. Ultrason., Ferroelec., Freq. Contr. 38 (1991) 100-108. 
[4] R. E. Davidsen, J. A. Jensen, S. W. Smith, Two-dimensional random arrays for real time volumetric imaging, Ultrason. Imaging 16 (3) (1994) $143-163$.

[5] S. S. Brunke, G. R. Lockwood, Broad-bandwidth radiation patterns of sparse two-dimensional vernier arrays, IEEE Trans. Ultrason., Ferroelec., Freq. Contr. 44 (5) (1997) 1101-1109.

[6] J. T. Yen, J. P. Steinberg, S. W. Smith, Sparse 2-D array design for real time rectilinear volumetric imaging, IEEE Trans. Ultrason., Ferroelec., Freq. Contr. 47 (1) (2000) 93-110.

[7] A. Austeng, S. Holm, Sparse 2-D arrays for 3-D phased array imaging - design methods, IEEE Trans. Ultrason., Ferroelec., Freq. Contr. 49 (8) (2002) 1073-1086.

[8] M. Karaman, I. O. Wygant, O. Oralkan, B. T. Khuri-Yakub, Minimally redundant 2-D array designs for 3-D medical ultrasound imaging, IEEE Trans. Med. Imag. 7 (2009) 1051-1061.

[9] B. Savord, R. Solomon, Fully sampled matrix transducer for real time 3D ultrasonic imaging, in: Proc. IEEE Ultrason. Symp., Vol. 1, 2003, pp. 945-953.

[10] T. Halvorsrod, W. Luzi, T. Lande, A log-domain $\mu$ beamformer for medical ultrasound imaging systems, IEEE Trans. Circuits Syst. I, Reg. Papers 52 (12) (2005) 2563-2575. doi:10.1109/TCSI.2005.857544.

[11] S. Blaak, Z. Yu, G. Meijer, C. Prins, C. Lancee, J. Bosch, N. de Jong, Design of a micro-beamformer for a $2 \mathrm{D}$ piezoelectric ultrasound transducer, in: Proc. IEEE Ultrason. Symp., 2009, pp. 1338-1341. doi:10.1109/ULTSYM.2009.5441534.

[12] I. Cicek, A. Bozkurt, M. Karaman, Design of a Front-End Integrated Circuit for 3D Acoustic Imaging Using 2D CMUT Arrays, IEEE Trans. U1trason., Ferroelec., Freq. Contr. 52 (12) (2005) 2235-2241.

[13] I. O. Wygant, X. Zhuang, D. T. Yeh, O. Oralkan, A. S. Ergun, M. Karaman, B. T. Khuri-Yakub, Integration of 2D CMUT Arrays with Front-End Electronics for Volumetric Ultrasound Imaging, IEEE Trans. Ultrason. Ferroelec., Freq. Contr. 55 (2) (2008) 327-341.

[14] A. Bhuyan, J. W. Choe, B. C. Lee, I. O. Wygant, A. Nikoozadeh, Ö. Oralkan, B. T. Khuri-Yakub, Integrated Circuits for Volumetric U1trasound Imaging With 2-D CMUT Arrays, IEEE Trans. Ultrason., Ferroelec., Freq. Contr. 7 (6) (2013) 796-804

[15] C. Daft, P. Wagner, B. Bymaster, S. Panda, K. Patel, I. Ladabaum, CMUTs and electronics for 2D and 3D imaging: Monolithic integration, in-handle chip sets and system implications, in: Proc. IEEE Ultrason. Symp., 2005, pp. 463-474.

[16] G. Gurun, C. Tekes, J. Zahorian, T. Xu, S. Satir, M. Karaman, J. Hasler, F. L. Degertekin, Single-Chip CMUT-on-CMOS Front-End System for Real-Time Volumetric IVUS and ICE Imaging, IEEE Trans. Ultrason., Ferroelec., Freq. Contr. 61 (2) (2014) 239-250.

[17] R. Sampson, M. Yang, S. Wei, C. Chakrabarti, T. F. Wenisch, Sonic Millip3De: A massively parallel 3D-stacked accelerator for 3D ultrasound, IEEE 19th International Symposium on High Performance Computer Architecture (2013) 318-329.

[18] IEC, Medical electrical equipment - part 2-37: Particular requirements for the basic safety and essential performance of ultrasonic medical diagnostic and monitoring equipment, Tech. Rep. IEC 60601-2-37, International Electrotechnical Commission, edition 2.1 2015-06 (2015).

[19] C. E. Morton, G. R. Lockwood, Theoretical assessment of a crossed electrode 2-D array for 3-D imaging, in: Proc. IEEE Ultrason. Symp., 2003, pp. 968-971.

[20] M. F. Rasmussen, J. A. Jensen, 3D ultrasound imaging performance of a row-column addressed 2D array transducer: a simulation study, in: Proc. SPIE Med. Imag., 2013, pp. 1-11, 86750C.

[21] M. F. Rasmussen, J. A. Jensen, 3-D ultrasound imaging performance of a row-column addressed 2-D array transducer: A measurement study, in: Proc. IEEE Ultrason. Symp., 2013, pp. 1460-1463.

[22] C. E. M. Démoré, A. Joyce, K. Wall, G. Lockwood, Real-time volume imaging using a crossed electrode array, IEEE Trans. Ultrason., Ferroelec., Freq. Contr. 56 (6) (2009) 1252-1261

[23] A. W. Joyce, G. R. Lockwood, Variably polarized ceramic for passive aperture apodization, in: Proc. IEEE Ultrason. Symp., 2012, pp. 15571559

[24] T. L. Christiansen, M. F. Rasmussen, J. A. Jensen, E. V. Thomsen, Rowcolumn addressed 2-D CMUT arrays with integrated apodization, in: Proc. IEEE Ultrason. Symp., 2014, pp. 600-603.

[25] C. H. Seo, J. T. Yen, 64 x 64 2-D array transducer with row-column ad- dressing, in: Proc. IEEE Ultrason. Symp., Vol. 1, 2006, pp. 74-77.

[26] C. H. Seo, J. T. Yen, 256x256 2-D array transducer with row-column addressing for 3-D imaging, in: Proc. IEEE Ultrason. Symp., 2007, pp. 2381-2384.

[27] C. H. Seo, J. T. Yen, Recent results using a 256 x 256 2-D array transducer for 3-D rectilinear imaging, in: Proc. IEEE Ultrason. Symp., Vol. 1-4, 2008, pp. 1146-1149.

[28] C. H. Seo, J. T. Yen, A 256 x 256 2-D array transducer with row-column addressing for 3-D rectilinear imaging, IEEE Trans. Ultrason., Ferroelec., Freq. Contr. 56 (4) (2009) 837-847.

[29] J. T. Yen, C. H. Seo, S. I. Awad, J. S. Jeong, A dual-layer transducer array for 3-D rectilinear imaging, IEEE Trans. Ultrason., Ferroelec., Freq. Contr. 56 (1) (2009) 204-212.

[30] A. S. Logan, L. L. P. Wong, J. T. W. Yeow, 2-D CMUT wafer bonded imaging arrays with a row-column addressing scheme, in: Proc. IEEE Ultrason. Symp., 2009, pp. 984-987.

[31] A. S. Logan, L. L. P. Wong, A. I. H. Chen, J. T. W. Yeow, A 32 x 32 element row-column addressed capacitive micromachined ultrasonic transducer, IEEE Trans. Ultrason., Ferroelec., Freq. Contr. 58 (6) (2011) 12661271.

[32] R. J. Zemp, W. Zheng, P. Zhang, Feasibility of top-orthogonal-to-bottom electrode (TOBE) 2D CMUT arrays for low-channel-count 3D imaging, in: Proc. IEEE Ultrason. Symp., 2011, pp. 498-502.

[33] A. Sampaleanu, P. Zhang, A. Kshirsagar, W. Moussa, R. Zemp, Toporthogonal-to-bottom-electrode (TOBE) CMUT arrays for 3-D ultrasound imaging., IEEE Trans. Ultrason., Ferroelec., Freq. Contr. 61 (2) (2014) 266-276

[34] R. K. W. Chee, A. Sampaleanu, D. Rishi, R. J. Zemp, Top orthogonal to bottom electrode (TOBE) 2-D CMUT arrays for 3-D photoacoustic imaging, IEEE Trans. Ultrason., Ferroelec., Freq. Contr. 61 (8) (2014) 1393-1395.

[35] M. F. Rasmussen, T. L. Christiansen, E. V. Thomsen, J. A. Jensen, 3-D imaging using row-column-addressed arrays with integrated apodization - Part I: Apodization design and line element beamforming, IEEE Trans. Ultrason., Ferroelec., Freq. Contr. 62 (5) (2015) 947-958.

[36] T. L. Christiansen, M. F. Rasmussen, J. P. Bagge, L. N. Moesner, J. A. Jensen, E. V. Thomsen, 3-D imaging using row-column-addressed arrays with integrated apodization - part II: Transducer fabrication and experimental results, IEEE Trans. Ultrason., Ferroelec., Freq. Contr. 62 (5) (2015) 959-971.

[37] A. Zeshan, X. Zhang, Ö. Oralkan, F. Y. Yamaner, 2D CMUT Array Based Ultrasonic Micromanipulation Platform, in: Proc. IEEE Ultrason. Symp., 2016, pp. $1-4$

[38] J. A. Jensen, H. Holten-Lund, R. T. Nilsson, M. Hansen, U. D. Larsen, R. P. Domsten, B. G. Tomov, M. B. Stuart, S. I. Nikolov, M. J. Pihl, Y. Du, J. H. Rasmussen, M. F. Rasmussen, SARUS: A synthetic aperture realtime ultrasound system, IEEE Trans. Ultrason., Ferroelec., Freq. Contr. 60 (9) (2013) 1838-1852.

[39] M. Engholm, T. L. Christiansen, C. Beers, J. P. Bagge, L. N. Moesner, H. Bouzari, A. Lei, M. Berkheimer, M. B. Stuart, J. A. Jensen, E. V. Thomsen, A hand-held row-column addressed CMUT probe with integrated electronics for volumetric imaging, in: Proc. IEEE Ultrason. Symp., 2015, pp. 1-4. doi:10.1109/ULTSYM.2015.0143.

[40] K. K. Park, H. J. Lee, M. Kupnik, B. T. Khuri-Yakub, Fabrication of capacitive micromachined ultrasonic transducers via local oxidation and direct wafer bonding, J. Microelectromech. S. 20 (1) (2011) 95-103.

[41] I. Ladabaum, P. Wagner, C. Zanelli, J. Mould, G. Wojcik, Silicon substrate ringing in microfabricated ultrasonic transducers, in: Proc. IEEE Ultrason. Symp., 2000, pp. 943-946.

[42] M. S. S. Bolorforosh, Microgrooves for apodization and focussing of wideband clinical ultrasonic transducer, US Patent 5,371,717 (June 1994).

[43] J. A. Jensen, H. Holten-Lund, R. T. Nilsson, M. Hansen, U. D. Larsen, R. P. Domsten, B. G. Tomov, M. B. Stuart, S. I. Nikolov, M. J. Pihl, Y. Du, J. H. Rasmussen, M. F. Rasmussen, Sarus: A synthetic aperture real-time ultrasound system, IEEE Trans. Ultrason., Ferroelec., Freq. Contr. 60 (9) (2013) 1838-1852.

[44] M. Engholm, H. Bouzari, J. A. Jensen, E. V. Thomsen, Capacitive substrate coupling of rowcolumn-addressed 2-D CMUT arrays, in: Proc. IEEE Ultrason. Symp., 2016, pp. 1-4.

[45] J. A. Jensen, N. B. Svendsen, Calculation of pressure fields from arbitrarily shaped, apodized, and excited ultrasound transducers, IEEE Trans. 
Ultrason., Ferroelec., Freq. Contr. 39 (1992) 262-267.

[46] J. A. Jensen, Field: A program for simulating ultrasound systems, Med. Biol. Eng. Comp. 10th Nordic-Baltic Conference on Biomedical Imaging, Vol. 4, Supplement 1, Part 1 (1996) 351-353.

[47] T. L. Szabo, Diagnostic ultrasound imaging: Inside out, 2nd Edition, Elsevier (Oxford, UK), 2014.

[48] S. Holbek, T. L. Christiansen, M. F. Rasmussen, M. B. Stuart, E. V. Thomsen, J. A. Jensen, 3-D vector velocity estimation with row-column addressed arrays, in: Proc. IEEE Ultrason. Symp., 2015, pp. 1-4.

[49] S. Holbek, T. L. Christiansen, M. Engholm, A. Lei, M. B. Stuart, C. Beers, L. N. Moesner, J. P. Bagge, E. V. Thomsen, J. A. Jensen, 3-D vector flow using a row-column addressed CMUT array, in: Proc. SPIE Med. Imag., Vol. 9790, 2016, pp. 979005-979005-8.

[50] T. L. Christiansen, J. A. Jensen, E. V. Thomsen, Acoustical cross-talk in row-column addressed 2-D transducer arrays for ultrasound imaging, Ultrasonics 63 (2015) 174-178. doi:10.1016/j.ultras.2015.07.008.

[51] B. Bayram, M. Kupnik, G. G. Yaralioglu, Ö. Oralkan, A. S. Ergun, D.-S. Lin, S. H. Wong, B. T. Khuri-Yakub, Finite element modeling and experimental characterization of crosstalk in 1-d CMUT arrays, IEEE Trans. Ultrason., Ferroelec., Freq. Contr. 54 (2) (2007) 418-430.

[52] K. K. Park, H. J. Lee, M. Kupnik, Ö. Oralkan, B. T. Khuri-Yakub, Fabricating capacitive micromachined ultrasonic transducers with direct waferbonding and locos technology, in: IEEE International Conference on Micro Electro Mechanical Systems, 2008, pp. 339-342.

[53] G. G. Yaralioglu, A. S. Ergun, B. Bayram, E. Hæggström, B. T. KhuriYakub, Calculation and measurement of electromechanical coupling coefficient of capacitive micromachined ultrasonic transducers, IEEE Trans. Ultrason., Ferroelec., Freq. Contr. 50 (4) (2003) 449-456.

[54] A. Lei, S. E. Diederichsen, S. M. Hansen, M. B. Stuart, H. Bouzari, J. A. Jensen, E. V. Thomsen, Output pressure and harmonic characteristics of a CMUT as function of bias and excitation voltage, in: Proc. IEEE Ultrason. Symp., IEEE, 2015, pp. 1-4.

[55] FDA, Information for manufacturers seeking marketing clearance of diagnostic ultrasound systems and transducers, Tech. rep., Center for Devices and Radiological Health, United States Food and Drug Administration (2008).

[56] H. Bouzari, M. Engholm, C. Beers, S. I. Nikolov, M. B. Stuart, E. V. Thomsen, J. A. Jensen, Imaging performance assesment of CMUT and PZT row-column-addressed 2-D array probes, IEEE Trans. Ultrason., Ferroelec., Freq. Contr. Submitted. 